\title{
Successful management of unremitting spasm of the nongrafted right coronary artery after off-pump coronary artery bypass grafting
}

Stefano Schena, MD, PhD, ${ }^{a}$ Troy Wildes, MD, ${ }^{\mathrm{b}}$ Michael A. Beardslee, MD, ${ }^{\mathrm{c}}$ John M. Lasala, MD, PhD, ${ }^{\mathrm{c}}$ Ralph J. Damiano Jr, MD, a and Jennifer S. Lawton, MD, ${ }^{a}$ St Louis, Mo

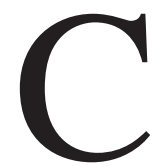

oronary artery spasm may complicate the immediate postoperative period after coronary artery bypass grafting (CABG). Spasm has also been described as occurring after off-pump CABG (OPCAB) and has been attributed to both technical and iatrogenic causes. In reported cases, removal of the causative factor or intracoronary nitroglycerine has eliminated the spasm. To our knowledge, this is the first report of a patient who underwent successful OPCAB and experienced a persistent spasm of the nongrafted right coronary artery despite intracoronary administration of nitroglycerine and nicardipine. Cardiogenic shock was improved only after emergent insertion of an intra-aortic balloon pump (IABP) and extensive angioplasty and stenting of the involved vessel.

\section{Clinical Summary}

A 49-year-old man, who had percutaneous transluminal coronary angioplasty and stent to the proximal left anterior descending artery (LAD) 5 months previously, presented with recurrent

From the Division of Cardiothoracic Surgery, ${ }^{a}$ Department of Anesthesiology, ${ }^{\mathrm{b}}$ and Division of Cardiology, ${ }^{\mathrm{c}}$ Washington University School of Medicine and Barnes-Jewish Hospital, St Louis, Mo, USA.

Address for reprints: Jennifer S. Lawton, MD, Division of Cardiothoracic Surgery, Washington University School of Medicine, $660 \mathrm{~S}$. Euclid Ave, Campus Box 8234, St Louis, MO 63110-1013 (E-mail: lawtonj@wustl.edu).

J Thorac Cardiovasc Surg 2007;133:1649-50

$0022-5223 / \$ 32.00$

Copyright (C) 2007 by The American Association for Thoracic Surgery doi:10.1016/j.jtcvs.2007.01.073 angina and $60 \%$ in-stent stenosis with extension into the left main and compromise of the ostial left circumflex artery. A $30 \%$ eccentric proximal lesion was visualized on the dominant right coronary (Figure 1, $A$ ). Left ventricular function was well preserved. The patient underwent uneventful OPCAB using the left internal thoracic artery to the LAD and left radial artery graft to the obtuse marginal. No vasoactive substances were administered, and ultrasonic flow was excellent in both of the grafts.

The postoperative electrocardiogram (EKG) was unremarkable, and the hemodynamic status was satisfactory; a 325-mg dose of acetylsalicylic acid was administered and the patient underwent uneventful extubation. Shortly thereafter, he experienced chest pain followed by persistent hypotension requiring phenylephrine infusion and EKG changes inferiorly. Emergency transthoracic echocardiogram demonstrated a significant reduction in the right ventricular function, and the patient was immediately transported to the cath lab. Angiography confirmed patency of the bypass grafts, minimal spasm in the radial artery graft, worsening of the native LAD lesion, and diffuse spasm of the native right coronary artery (RCA; Figure 1, B). Intraluminal administration of nitroglycerine and nicardipine did not improve the spasm. An IABP was placed and 2 overlapping Cypher drug-eluting stents were placed in the main RCA after multiple balloon angioplasties. Residual distal RCA spasm with systolic posterior descending artery compression was noted (Figure 2). The patient was treated with dobutamine and milrinone and subsequently discharged on the 8th postoperative day on clopidogrel and amlodipine.

At 3-month follow-up, the patient was well with no recurrence of angina.
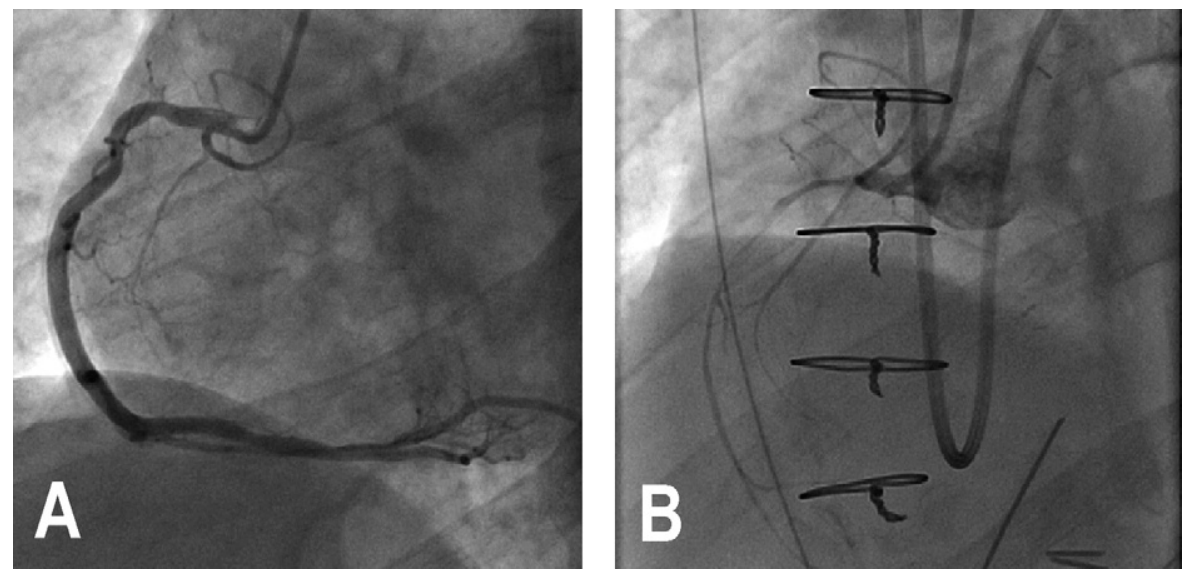

Figure 1. Right coronary artery at preoperative (A) and postoperative (B) angiogram. 


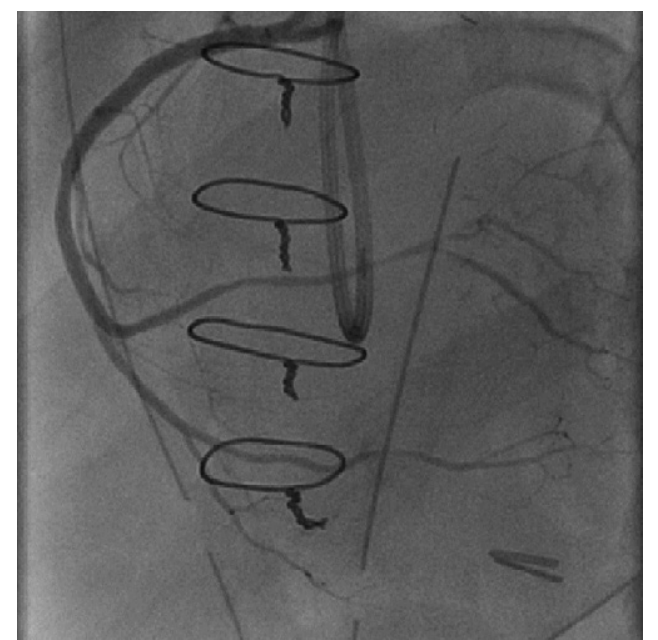

Figure 2. Right coronary artery appearance after angioplasty and stenting.

\section{Discussion}

Coronary artery spasm is a known cause of angina and ischemia in patients with or without coronary artery structural lesions (Prinzmetal angina). Spasm may occur during or after $\mathrm{CABG}$, more commonly involves the RCA, and has an incidence of $0.8 \%$ to $1.3 \% .^{1}$ The real incidence remains uncertain as an exact diagnosis can only be achieved by coronary angiography. Manifestations of postoperative coronary artery spasm range from arrhythmia and ST segment elevation to hemodynamic instability and cardiac arrest.

Successful pharmacologic treatment of spasm of the RCA following OPCAB of the left diseased system has been report$\mathrm{ed},{ }^{2}$ as has the unsuccessful treatment of a pharmacologically unresponsive coronary spasm following OPCAB. ${ }^{3}$ To the best of our knowledge, this is the first report of successfully treated spasm in a nonsurgically manipulated vessel that did not resolve with intraluminal vasodilator administration.

Many etiologic factors have been proposed to explain the pathogenesis of postoperative coronary arterial spasm: trauma due to surgical manipulation or to compression by chest tubes, ${ }^{4}$ hypomagnesemia, alkalotic blood $\mathrm{pH}$, alpha adrenergic stimulation, hypothermia, and damaged platelet release of vasospastic amine (ie, thromboxane A2). ${ }^{5}$ In the case presented, the differential diagnosis could include: spasm due to heart manipulation, an increased propensity for vasospasm combined with some unrecognized electrolyte abnormality, or external compression from the 2 silastic chest tubes. Manipulation of the heart was performed with only an apical suction cup and topical suction on each of the vessels bypassed, which makes manipulation of the RCA an unlikely etiology for the severe spasm noted. A predilection for vasospasm may have contributed in the patient described, as the spasm was refractory to both intracoronary nitroglycerin and nicardipine and the radial graft was also involved. External compression from the silastic tubes seems unlikely as the RCA demonstrated diffuse spasm along its entire course and the mildly spastic radial artery graft was not compressed.

Native vessel coronary spasm should remain in the differential diagnosis of EKG changes following CABG, and coronary angiography represents the fastest and most accurate diagnostic option. We present a case of successfully treated, diffuse, and hemodynamically significant spasm in the nongrafted RCA that was refractory to intracoronary vasodilator agents and required extensive angioplasty and stenting.

\section{References}

1. Buxton AE, Goldberg S, Harken AH, Hirshfeld Jr JW, Kastor JA. Coronary artery spasm immediately following coronary artery bypass surgery: recognition and management. N Engl J Med. 1981;304:124953.

2. Bossert T, Bittner HB, Gummert JF, Mohr FW. Coronary artery spasm of the native right coronary artery during off-pump coronary surgery of the left coronary artery system. Clin Res Cardiol. 2006; 95:115-8.

3. Ueno T, Ikeda K, Nakashima A. Vasodilator resistant lethal spasm after uncomplicated off-pump coronary surgery. Asian Cardiovasc Thorac Ann. 2006;14:158-60.

4. Marques KM, Jensen EE, Huybregts RA. Profound coronary spasm caused by a mediastinal draining tube. Heart. 2006;92:514.

5. Buxton AE, Hirshfeld Jr JW, Untereker WJ, Goldberg S, Harken AH, Stephenson LW, et al. Perioperative coronary arterial spasm: long term follow-up. Am J Cardiol. 1982;50:444-51. 